\title{
Towards automation of measurement processes of surface water parameters by a remote-controlled catamaran
}

\author{
J. WIORA*, A. KOZYRA, and A. WIORA \\ Institute of Automatic Control, Silesian University of Technology, 16 Akademicka St., 44-100 Gliwice, Poland
}

\begin{abstract}
This paper describes a way of determining selected water parameters using a prototype of a remote-controlled catamaran. The remote controlling allows to steer the boat and to manage the measurement process from the shore. It is possible to monitor the water parameters online as well as to store them and analyze them afterwards. The measured parameters are determined mainly using potentiometric methods and include several ion concentrations. The system is orientated towards monitoring breeding ponds or other similar surface waters. The mechanical construction of the catamaran, its electronic circuits and implemented software are described in detail in the paper. Conclusions obtained from preliminary tests are also included. The described construction allows analysts to perform simple and inexpensive remote measurements or assessments of water quality and reduces the time of such analysis in comparison to traditional sampling.
\end{abstract}

Key words: measurement automation, remote-controlled boat, environmental water analysis, potentiometry.

\section{Introduction}

Growing awareness of the impact of pollution on human and animal life has led to monitoring of water parameters becoming more and more frequent. The acquisition methods may be as easy as grab sampling [1] and as advanced as satellite-based remote sensing [2]. The simplest monitoring of water quality on a local scale can be realized by portable or hand-held devices, however this has many limitations [3]. On the other hand, well-developed monitoring systems can be integrated into a network $[4,5]$, enabling analysis of pollution propagations on a global scale [6] or may be assembled in a mobile monitoring station allowing for online measurements of water quality [7]. A drawback of hand-held devices stems from the fact that they require providing the measurement devices on the target site. If possible, the samples are taken near shores or bridges [8], otherwise a boat has to be used [9]. Using a remote-controlled watercraft is far more convenient; it can be as a catamaran, which transports a sample from the target place or brings the measurement devices onto the water and stores the results or transmits them online [10].

Water is the most common solvent in the environment, on which the existence of living organisms is founded. According to Polish regulations [11], water quality (purity) is classified into five classes. Regulation [11] is related to the introduction of the provisions of EU Directive No. 2000/60/EC [12] into Polish law. Class I contains the cleanest water of a very good quality. It can be consumed without any anthropogenic impacts. Classes II and III denote water of good and satisfactory quality, respectively. It can be intended for consumption after appropriate pretreatment. The anthropogenic influence is small or moderate. Classes IV and V are regarded as water

*e-mail: jozef@wiora.pl of poor or unsatisfactory quality, where extinction of some or most living organisms has occurred as a result of anthropogenic transformation. Physicochemical parameters describing water quality include, i.a., temperature, $\mathrm{pH}$, conductivity at $20^{\circ} \mathrm{C}$, concentrations of suspended solids, dissolved oxygen, nitrates, sulphates, calcium, magnesium, chloride and free cyanide. Some of these parameters, listed in Annex V of the Directive, can be controlled using electrochemical sensors. They are characterized by moderate accuracy, low cost and low power consumption [13-15]. This provides the opportunity to perform remote measurements and automations. Sensors and measurement devices used in these methods do not require high power and can also be easily miniaturized. In this way, measurements can be carried out in any place. Potentiometric sensors have, however, some limitations. More pros and cons of using ion-selective electrodes, i.a. in a hydroponic application, are enumerated in the work of Kim et al. [16]. Comparable results can be obtained using fibre optic chemical sensors [17]. Other water parameters which need to be determined, and those that could not be measured online, such as the number of coliform bacteria or concentration of trace metals, could be assessed in a laboratory based on water samples taken in the same place where the measurements are carried out automatically [1].

Electrochemical methods include conductometry and potentiometry. Conductometry is mainly applied for general assessment of water purity without pointing out a particular chemical species. The measurement relies on measuring the alternative current flowing through a liquid sample in a cell built from two electrodes. A very simple relationship describes it: the higher the current, the more contaminated the water. The potentiometric method is more complicated. There are at least two electrodes, one ion-selective electrode (ISE) and one reference electrode, between which a potential difference appears. Its value, $E$, is proportional to the logarithm of concentration, 
$c$, of a particular ion to which the electrode is sensitive and is described by the Nernst equation [18, 19]:

$$
E \propto \log c
$$

The most popular and commonly known ISE is the pH-electrode. In fact, selectivity of ISEs is finite, therefore during measurements of mixtures, a more complicated relationship should be applied, such as the Nikolsky-Eisenman one, where the potential is dependent on concentrations of all ions present in the mixture $[18,19]$ :

$$
E \propto \log \left(c_{1}+K_{2} c_{2}+K_{3} c_{3}+\ldots\right)
$$

where $K_{i}$ is the potentiometric selectivity coefficient of ion $i$ toward the ion on which the electrode is selective. Besides the complicated (non-linear) mathematical relationship, potentiometry still belongs to the cheapest and most attractive analytical methods [20] and therefore is frequently applied in automatic control of processes [21]. The possibility of miniaturization and producing chemically resistant electrodes enables the development of below $1 \mathrm{~cm}$ diameter sensors dedicated to in situ measurement of surface water with six months slope stability [22]. The sensing element of an ISE can be made from various materials. It can be glass, a composition of polyvinyl chloride (PVC) and some additives, crystal and others. The material determines the name of the ISE, e.g. glass electrode.

Studies of surface water contents are frequently performed in Poland, i.a. at Pławniowice reservoir [23], ponds near $\mathrm{Zn}-\mathrm{Pb}$ smelters [24], anthropogenic lakes, which were formerly brown coal excavation sites [25], the Dunajec river [26] and geothermal water sources [27]. Other important reasons for investigations of water parameters are changes resulting from decay processes, composting processes, and decomposition products of plant and animal. Near the sources of such processes, changes in water parameters are noticeable and monitoring can be used to locate the sources of water pollution, which are an important issue in environmental protection [28]. In order to contribute to the development of water monitoring techniques, the authors decided to start work on building a simple and low-cost prototype of a catamaran. It should be dedicated to potentiometric determination of particular ions in surface water such as ponds, lakes, reservoirs, wetlands, slow-flowing rivers, canals, open conduits and open sewers. It was planned that the catamaran would be a basis for further development of measurement techniques orientated towards environmental investigations of living conditions for breeding fishes. As a solution, a radio-controlled catamaran, driven from a shore a few hundred metres away, equipped with appropriate electronics and software was proposed. Online measurements performed by a remote-controlled watercraft have many benefits. They allow for continuous and rapid monitoring of selected parameters of surface water, without the the need to involve a technician, at a chosen place of a water reservoir, limited only by the maximum wireless link range [29]. This paper provides the detailed description of the prototype built to help other researchers having similar needs.

\section{Theoretical background}

In the literature, mainly two branches of watercrafts dedicated to measurements could be found. The first one are manned boats equipped with expensive measurement devices dedicated mainly to sea or ocean investigations. Such solutions are not preferable for small reservoirs. The second one are unmanned autonomous watercrafts [29]. In the case of small and moderate-size lake and river investigations, autonomy is not necessary, because an attendant of the craft has to be in the vicinity. An implementation of autonomy requires much effort during construction - cf. autonomous flying objects [30] or mobile platforms [31]. Measurement equipment is sometimes placed on a mini-catamaran with no propulsion and positioned by a rope [32].

Generally, a catamaran is a type of high-stability watercraft with low resistance. It has two parallel hulls joined together rigidly by a frame making a bridging structure [33]. Some small catamarans are run by one propeller and controlled by a rudder. Catamarans can have sails to produce motion [34]. But the most popular solution is applying of two propellers. This allows for both motion production and setting of the moving direction. Propellers can be driven by electric or combustion motors. Among electric motors, direct current (DC) motors are frequently used because the power supply of catamarans is usually a DC source. In cheaper solutions, brush DC motors are used. More efficient brushless DC motors require complex and expensive control [35]. Much more expensive and complicated combustion engines can be used in applications where wide range is essential. Energy density in gasoline is about fifty times higher than in batteries.

Watercrafts can be fed i.a. by solar cells, primary or rechargeable batteries or combustion motors/generators. Nowadays, lithium polymer batteries (LiPo) are very popular. The types of battery are characterized by a very high performance at a relatively small size and weight. Working with this kind of power supply, however, requires some experience and care. The nominal voltage of a single cell is $3.7 \mathrm{~V}$, whereas the maximum value is $4.2 \mathrm{~V}$ and the minimum is $3.0 \mathrm{~V}$. Mechanical faults, short circuits or exceeding the limits may damage the battery and other devices in its vicinity due to explosion or fire. An alternative way of power supply is by using supercapacitors which stand out for their high power density, extremely long live and many other benefits [36].

The primary element of a contemporary electronic device is a microprocessor. At present, we can find general-purpose microprocessors with very high performance used in personal computers and servers. Microprocessors integrated with memories and peripheries in one chip, known as microcontrollers ( $\mathrm{uCs}$ ), belong to another branch. They are used in devices that have dedicated tasks, creating embedded systems. Depending on the complexity of the tasks, the uCs can be very simple with extremely low power consumption up to multi-core uCs with very high performance as used i.a. in smartphones. They are produced by dozens of firms in many variants, so the proper choice of a $\mathrm{uC}$ adequate for an application is an important task. 
The catamaran may be connected with a shore station in several ways. The simplest is cable connection. This allows for communication in the range of tens of metres. Longer cables are not suitable due to possible tangles. Wireless connections are more suitable. Between them, there are ultrasonic, infrared or radio connections. They differ in available ranges and power needed to maintain communication. Using a radio connection, one can choose between many available solutions. Minimizing the cost of the application, commonly used standards are suggested, such as the $27 \mathrm{MHz}$ band [8], Bluetooth, Wi-Fi or ZigBee. There are known applications of Bluetooth (IEEE 802.15.1) standard for remote-controlled watercraft [37]; however, the range is limited to $100 \mathrm{~m}$. Such a range is not sufficient for our application. The Wi-Fi (IEEE 802.11) standard gives comparable range, allows a much higher data rate but consumes more energy. Applications of the standard to a boat prototype [38] or a sensor network node [5] are also known. A relatively new technology, WiMAX (IEEE 802.16), is still expensive but allows high data rates and big ranges up to $55 \mathrm{~km}$. Both Wi-Fi and WiMAX technologies engage much more electronics and software, whereas high date rate is not necessary here. The most suitable for wireless control and monitoring applications is the ZigBee (IEEE 802.15.4) standard. Its devices consume low power. The typical line-of-sight range is $100 \mathrm{~m}$ but some devices allow a bigger range.

Building a measurement transducer or transmitter requires not only using mechanical and electrical parts, but also developing appropriate software. Very often two distinct computer programs are required. The first one is dedicated to $\mathrm{uC}$, which manages the measurement process - in our case, it moves the catamaran to a selected place, acquires measurement data and transmits them to the shore station. The other program is associated with a human-machine interface. The interface may be integrated with the transducer - in this case, the programs can also be integrated with each other - but very often the interface is realized on a PC and the program is completely different from the first one.

It is necessary to choose a programming language before writing a program. The choice depends on several aspects. The most important include: the kind of project (numerical calculations, decision making application, web-based application) [39], software attribution (cross-platform or dedicated platform, scalability), availability and cost of developing software (editing environment, compiler, debugger), libraries and technical support, existence of discussion groups, and finally skills and philosophy of the programmer.

To program an embedded system, three languages are frequently used. They are: C (or its extensions), BASIC and assembly. The most popular is C. It is a high-level structural programming language that allows also for low-level control of the compiled code. For uCs, the $\mathrm{C}$ language is extended compared with the ANSI C standard, allowing access to inputs/outputs, timers and interrupts [40].

There are plenty of possible languages in which a modern PC application may be written. Most of them allow for the creation of a graphical user interface (GUI). Among metrologists, the National Instruments LabVIEW is very popular, due to its extremely fast development of software, recalculating and visualizing measurement data acquired by measurement instruments and connected to PCs through data acquisition cards. The LabVIEW is an environment for the creation of both GUI and programs in the $\mathrm{G}$ language. $\mathrm{G}$ is a dataflow programming language where code is written graphically using diagrams and icons [41]. Some properties of the environment are described by Whitley [42].

\section{Experimental}

3.1. Chemicals and calibration procedures. Measurement experiments were conducted using different configuration of sensors than it is illustrated in Fig. 2. A combination ERH-11 $\mathrm{pH}$ and reference electrode, purchased from Hydrometr, Gliwice, Poland, with a glass bulb ion-selective membrane was used. Its $\mathrm{pH}$ measuring range is $0-14$ and resistance of its membrane at $20^{\circ} \mathrm{C}$ is $100-200 \mathrm{M} \Omega$. As the $\mathrm{Cl}^{-}$sensitive electrode, an ECl-01 ISE with a polycrystalline membrane, also purchased from Hydrometr, was used. Its $\mathrm{pCl}$ measuring range is $0-5$ and resistance at $20^{\circ} \mathrm{C}$ is about $50 \mathrm{M} \Omega$. The main interfering ions are $\mathrm{S}^{2-}, \mathrm{I}^{-}, \mathrm{S}_{2} \mathrm{O}_{3}{ }^{2-}, \mathrm{Br}^{-}$and $\mathrm{OH}^{-}$

The $\mathrm{K}^{+}, \mathrm{Na}^{+}$and $\mathrm{Ca}^{2+}$ ISEs were prepared according to the procedure described below. Selectophore reagents, obtained from Fluka AG, Buchs, Switzerland, were used as membrane components. The composition of the membranes were as follows: for $\mathrm{K}^{+}$ISE: potassium ionophore III, potassium tetrakis(4-chlorophentyl)borate as lipophilic salt and bis(1-butylpentyl)adipate as plasticiser; for $\mathrm{Na}^{+}$ISE: sodium ionophor III and bis(1-butylpentyl)adipate as plasticiser; for $\mathrm{Ca}^{2+}$ ISE: calcium-ionophore I, potassium tetrakis(4-chlorophentyl)borate as lipophilic salt and bis(1-butylpentyl)-decan-1,10-diyl-digluterate as plasticiser. The high molecular weight poly(vinyl chloride) was a matrix used for the each membrane. Proportions of the components were the same as in the Selectophore manual [43]. The ISEs were built from the membranes put into Philips IS-561 electrode bodies (Gläsblaserei Möller, Zurich, Switzerland) and filled with $0.01 \mathrm{M}$ inner solutions.

The calibration of the $\mathrm{pH}$ electrode was performed using two buffers: $\mathrm{pH}=4 \pm 0.05$ and $\mathrm{pH}=10 \pm 0.05$ (POCh, Gliwice, Poland). The temperature of the buffers were the same as the temperature of water in the lake. The laboratory calibration of other ISEs was performed using five standard solutions for each electrode: from $\mathrm{pX}=1$ to $\mathrm{pX}=5$, where $\mathrm{X}$ is $\mathrm{Na}, \mathrm{K}, \mathrm{Ca}$ or $\mathrm{Cl}$. In the field, only two solutions were used with $\mathrm{pX}=1$ and $\mathrm{pX}=3$. To prepare all concentration standards, analytically pure salt of $\mathrm{NaCl}, \mathrm{KCl}$ and $\mathrm{CaCl}_{2}$ obtained from $\mathrm{POCH}$, Gliwice, Poland, have been used. Deionised water and class A Pyrex glassware were used for the preparation of all solutions.

Calibrations of all ISEs were carried out in the field immediately before putting them on the catamaran in order to minimize the effects of electrode drifts. To validate the obtained results, recalibration of the electrodes after measurements is recommended. Using the simplified calibration method of ISEs described elsewhere [44], the duration of the calibration pro- 
cedure is significantly reduced. In the method, appropriately prepared mixtures of standards are used instead of the pure solutions used in calibration methods recommended by IUPAC.

\subsection{System design.}

3.2.1. Mechanics. A remote-controlled construction of a catamaran, less than $1 \mathrm{~m}$ long, has been chosen as the most suitable for the planned investigations. A platform is used as a basis for fixing all control and measurement instruments (Fig. 1). All of the electronic instruments are sealed in hermetic boxes and fixed to the platform with screws. Cables connecting sensors with electronics are detachable. Now, BNC connectors are applied, which will be replaced by hermetic connectors and cable glands in the future. The hulls are made from suitably cut and

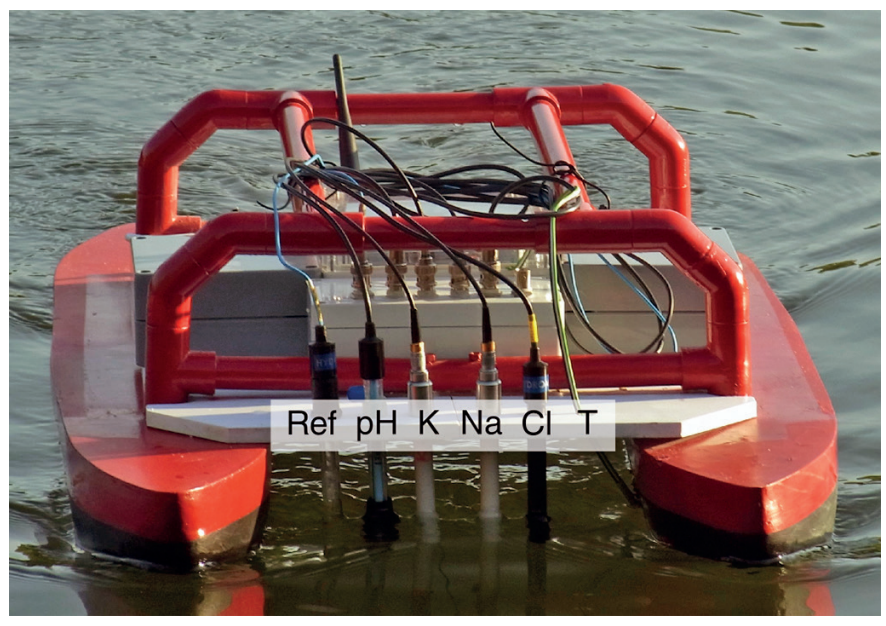

Fig. 1. The catamaran with selected configuration of sensors during tests. The sensors are: Ref - reference electrode; $\mathrm{pH}-\mathrm{pH}$ electrode; $\mathrm{K}$ - potassium ISE; $\mathrm{Na}$ - sodium ISE; $\mathrm{Cl}$ - chloride ISE; $\mathrm{T}$ - temperature sensor

joined together rescue buoys, strengthened by a glass cloth and an epoxy resin. Their sides have been aligned and protected against water by water glass and lacquer. The hulls have been joined by a frame made from polypropylene pipes. The catamaran is $85 \mathrm{~cm}$ long and $48 \mathrm{~cm}$ wide, while its platform is $50 \mathrm{~cm}$ long and $38 \mathrm{~cm}$ wide. The deadweight of the catamaran is about $5 \mathrm{~kg}$ and the total mass of the craft with electronics and batteries is less than $10 \mathrm{~kg}$.

3.2.2. Electrics. The primary purpose of building the catamaran is to perform measurements in any part of a water reservoir. Therefore, the system contains the necessary equipment to enable it. The concept of the electrical circuit is presented in Fig. 2. Bellow, short descriptions of each subsystem are given.

For driving the proposed catamaran, two DC commutator motors are used: these are in hermetic packaging, enabling their installation under water. The motors are appropriately adapted cheap $12 \mathrm{~V}$ bilge pumps. Their power rating is $20 \mathrm{~W}$. Two $5 \mathrm{~cm}$ diameter propellers have been chosen, allowing satisfactory speed (about $1 \mathrm{~m} / \mathrm{s}$ ) and reasonable power consumption. Each

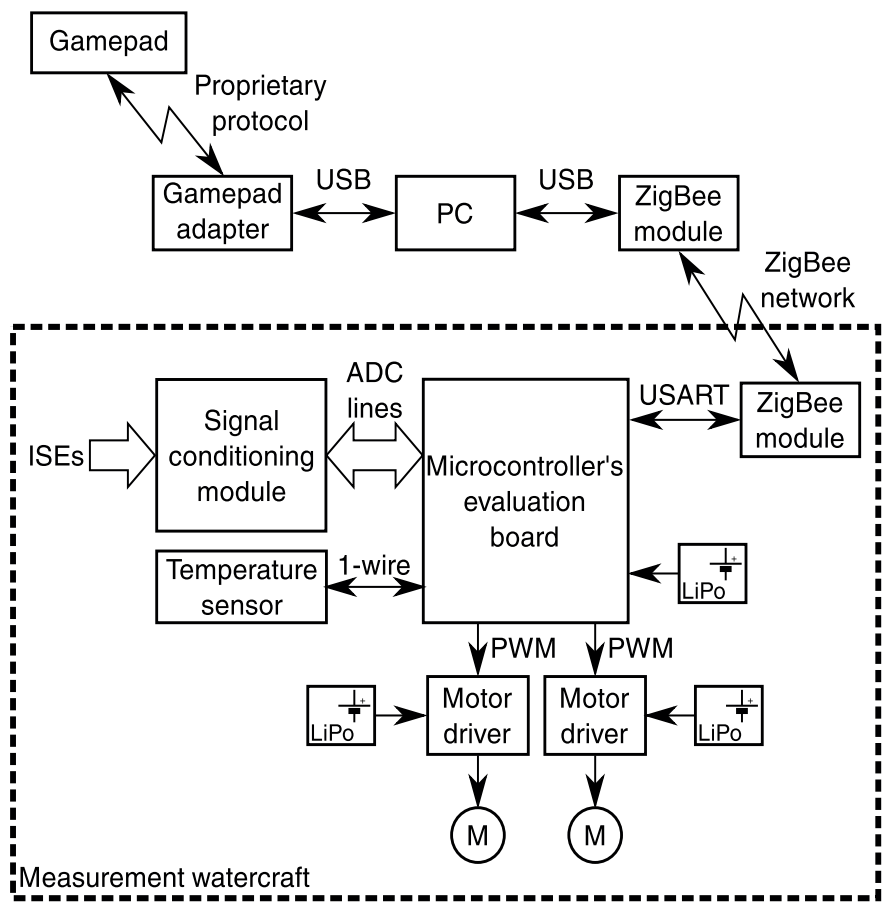

Fig. 2. Block diagram of the electronics of the proposed catamaran

motor is controlled by a pulse-width modulated (PWM) signal amplified by a Pololu 1451 module based on an STMicroelectronics VNH5019 H-bridge motor driver with MOSFET transistors, enabling linear varying of power and switching the motor polarity. This way, both the speed and direction of catamaran movement are easy to control. Additionally, it is also possible to measure the load current of the motors with the VNH5019 chip. An analysis of the signal allows for an appropriately earlier alerting of low battery power and may prevent users from leaving the catamaran away from shore in case of the battery discharging.

Balancing between costs, mass, power and complexity of usage, lithium polymer ( $\mathrm{LiPo}$ ) rechargeable batteries have been chosen, frequently used by both amateur and professional modellers. Two three-cell 2.2 Ah LiPo batteries are applied for feeding the motors and one two-cell $1 \mathrm{Ah}$ battery for the electronics. The electronics can work about $10 \mathrm{~h}$ with the battery. The time of motor working is dependent of load and is estimated to $3.5 \mathrm{~h}$ at $30 \%$ of maximum power.

The control unit embedded in the catamaran is based on the Analog Devices ADuC845. The choice comes from its high integration of peripheries, such as 24-bit analogue-to-digital converters (ADCs) and USART serial ports. Additionally, its MCS-51 core is still commonly used in industrial applications. In the work, the EVAL-ADUC845QSZ evaluation board is used, allowing a faster project realization. The main task of the control unit is the generation of PWM signals for the motors, acquisition of measurement results and communication with a user via a host computer and a wireless connection.

In the catamaran prototype, the number of measurement quantities has been limited. There are many quantities that are worth measuring, such as those mentioned in the EU Direc- 
tive [12] or investigated by others such as those described by [45]. As a starting point for further development, authors have decided to measure only several ion concentrations using the potentiometric method as well as temperature as necessary to accurately determine the concentrations. The quantities, which are monitored online and sent from the catamaran to the user, are as follows: water temperature, $\mathrm{pH}$ and concentrations of potassium, sodium and chloride ions. Any replacement of an ion-selective electrode with another one, which is selective towards a particular ion needed for environmental monitoring of breeding fishes or for other purposes, does not require any rebuilding of the system.

The measurement of water temperature investigated by the catamaran is carried out using the very popular and cheap Maxim DS18B20 integrated circuit. Its accuracy is $0.5^{\circ} \mathrm{C}$ over the range of $-10^{\circ} \mathrm{C}$ to $+85^{\circ} \mathrm{C}$, which is adequate for lake and river water. Communication with the microcontroller is achieved using the 1-wire protocol, allowing easy reading of the temperature expressed directly in ${ }^{\circ} \mathrm{C}$ without further recalculations. Together with the parasite power mode, it allows only one line, beside ground, for both supplying the circuit and transmitting data. The chip is put into a $3 \mathrm{~cm}$-long hermetically closed copper tube filled with a silica gel paste and is attached to the system using a $1 \mathrm{~m}$ long cable with a BNC connector at the end.

Working with ISEs requires usage of a dedicated signal conditioning module, among others due to their very high inner impedance, which demands much higher input impedance of successive circuits. Impedances of PVC ISEs are in the order of $1 \mathrm{M} \Omega$, while those of glass electrodes are in the order of $1 \mathrm{G} \Omega$. Modern Analog Devices AD8231 In-Amps are used with $10 \mathrm{G} \Omega$ input impedance, making the system suitable mainly for PVC electrodes. Working with glass electrodes with comparable inner impedance causes significant measurement error, which can partially be diminished by calibrations. Connections of the module are compatible with the $\mathrm{uC}^{\prime}$ s evaluation board connectors. The output signals of In-Amps are shifted by a half the reference voltage of ADC, allowing for usage of a unipolar converter during measurements of both positive and negative potentials of ISEs. Additional operational amplifiers (Op-Amps) included in the AD8231 chips are used to fix potentials of cable shields connected with ISEs in order to minimize electromagnetic interferences. Potentials of ISEs, after passing by the signal conditioning circuit described above, are measured by a $\Delta-\Sigma$ ADC integrated with the $\mathrm{uC}$.

The wireless transmission of measurement data and signals controlling the catamaran is realized based on the ZigBee standard. It uses the $2.4 \mathrm{GHz}$ frequency band. Two Digi International XBee Pro modules are used with a 1,500 m transmission range in open space allowing measurements on middle-size lakes. The first module, XBP24BZ7SIT-004, together with Sparkfun WRL-11373 XBee Explorer Regulated, links the TTL USART microcontroller's port with a wireless network. The second module, XBP24BZ7WIT-004, together with Sparkfun WRL-09819 XBee USB Adapter Board, links the wireless network with a PC's USB port. Such a solution allows for serial communication between $\mathrm{uC}$ and a program installed on a $\mathrm{PC}$ in the same way as using the commonly known RS-232 standard. Preliminary tests show that a bigger range than a few hundred metres is not necessary in this case, because an operator has to see the catamaran orientation to control its movement. The implemented bit rate of 9600 bps allows for real-time driving of the catamaran without noticeable delays.

In the case of transmission loss, the catamaran stops and waits for a new signal connection. This is the simplest possible solution. Future possible implementation of an inertial measurement unit (IMU) module with a satellite navigation system receiver will allow to return autonomously to a chosen location.

The motion control of the catamaran is achieved using the Hama X-Style RF USB gamepad dedicated for PCs. It gives much more flexible driving than using soft keys or a PC keyboard. Connection with the PC is realized wirelessly using a closed standard ensuring a $10 \mathrm{~m}$ range.

3.2.3. Software. The program has been written in $\mathrm{C}$ using the ARM Keil environment and the GNU GCC compiler. The environment is user-friendly and attached to the evaluation board, which is why it has been chosen. The program contains codes initializing the work of the $\mathrm{uC}$ and the infinite loop in which there are codes reading commands obtained from the ZigBee modem, interpreting the commands and generating signals for the motors accordingly, and sending data containing the water temperature and electrode potentials read from sensors to the ZigBee modem. An additional function, invoked by an interrupt, is responsible for reading the $\mathrm{ADC}$ registers and converting their values to potentials.

The LabVIEW environment was chosen to develop PC software, which contains both GUI and a set of instructions (program) written graphically. The front-end of the program is illustrated in Fig. 3. The main task of the application is archiving measurement data obtained from the measurement devices, as well as processing signals for driving the catamaran. The program starts with initializations of the gamepad and the ZigBee modem. After that, a loop is performed, in which a sequence of tasks is executed. First, based on data obtained from the gamepad, signals for motors are calculated, and values of

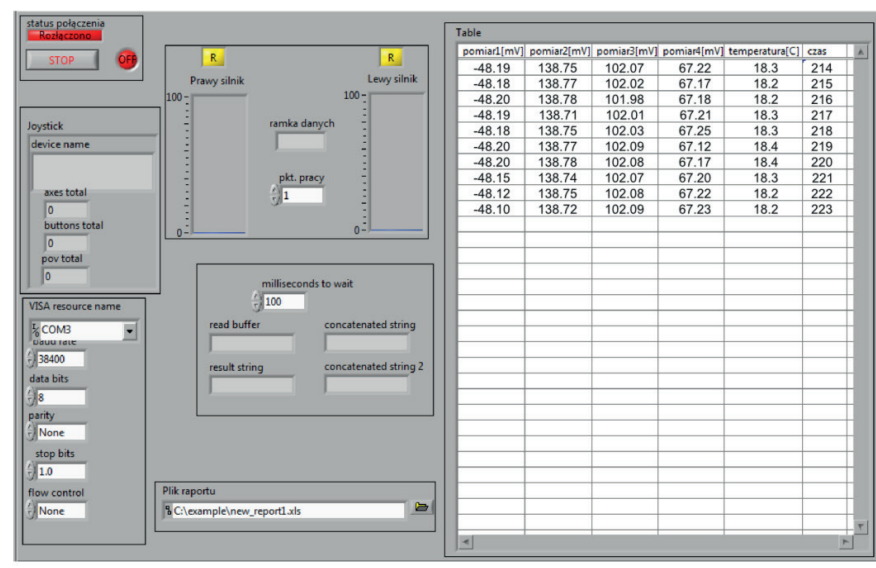

Fig. 3. Screen of LabVIEW front-end 

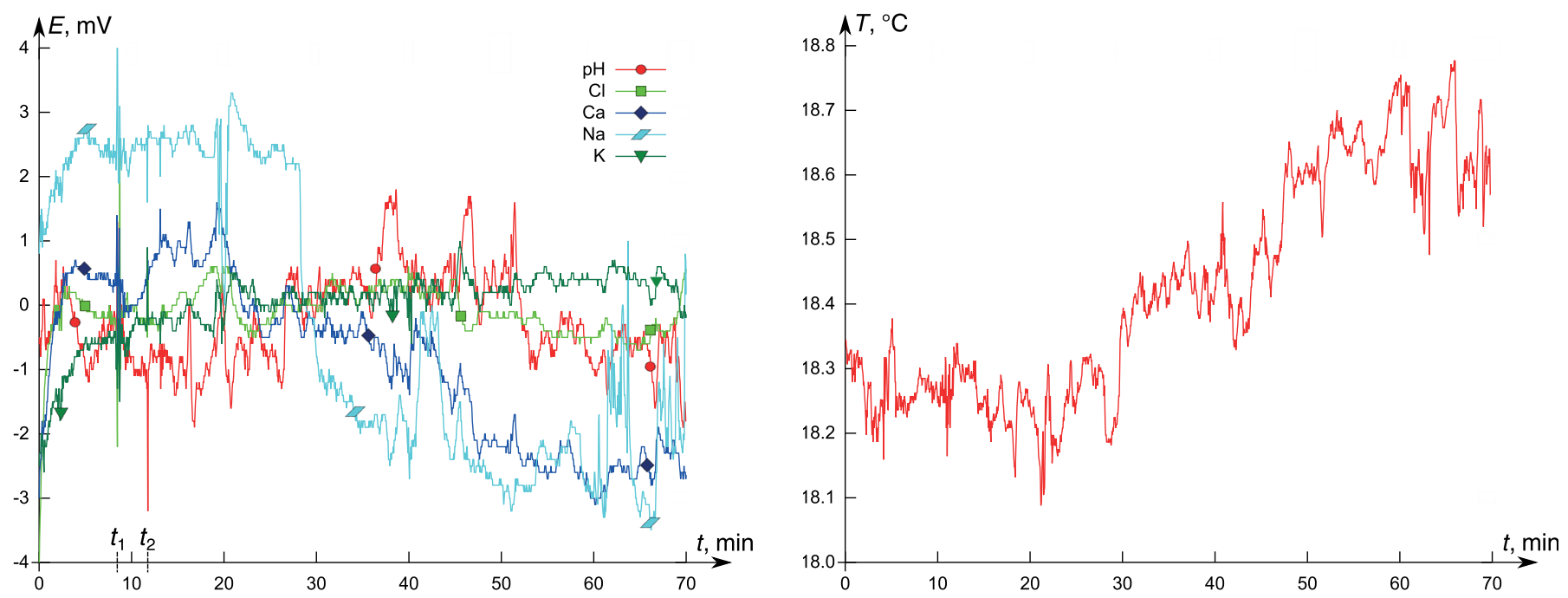

Fig. 4. Time responses of ISEs (left chart) and temperature (right chart) obtained during preliminary tests of the measurement catamaran conducted at a pond. Potentials of ISEs are offset in order to obtain comparable potentials for all ISEs

the signals are enclosed in data frames and sent to the modem. Next, a frame from the modem is received and measurement data are decoded. Finally, the data are appropriately formatted and saved on a disk as an Excel file, allowing further analysis using a spreadsheet. The GUI includes an on-off switch permitting communication with the catamaran, group boxes with information about the transmission parameters of the ZigBee wireless link and the status of the gamepad, bars visualizing the power of the motors and a table with measurement results.

\section{Results and discussion}

After assembling the catamaran in the laboratory, preliminary tests were performed on the Cegielnia pond, near Kujawska Street, Gliwice, Poland. The measurement data with potentials of ion-selective electrodes were presented and saved on the PC on the shore. It allows for further analysis and discussion. The data were collected for 70 minutes. Answers of the ISEs and temperature sensor are presented in Fig. 4. The temperature changes between 18.0 and $18.8^{\circ} \mathrm{C}$ and a slow increasing trend is observable due to warming of the water. The changes are, nevertheless, small and are not taken into considerations during calculations.

The measurement spans of the ISEs are very narrow. It means, that activities of ions in the pond do not change significantly. Nevertheless, the obtained information allow for drawing some conclusions.

In the first part of the plot, up to 4 minutes, all potentials increase. The ISEs were selective to both cations and ions, so an increase in concentrations should exhibit change in the chloride-selective electrode in opposite direction to the cation-selective electrodes. A much more probable cause of the phenomenon is a drift in potential of the reference electrode, which is common to all ISEs. This unstable time period should be rejected from further processing.
Other factors common to all ISEs are electric disturbances, which occur at time $t_{1}$ and $t_{2}$. The disturbances take only one sample. A very easy and effective filter for diminishing such disturbances is the moving-window median filter with three sample width, described broadly elsewhere [46]. The plots of the measurement data after rejection of the initial drift and filtering of impulses are presented in Fig. 5.

It may be easily seen that for such narrow measurement span, the quantization in the analogue-to-digital converter is noticeable. A usage of a converter with higher resolution would make the plots smoother. On the other hand, the higher resolution does not contribute additional valuable information because other factors, such as the electrode drifts, predominate measurement errors.

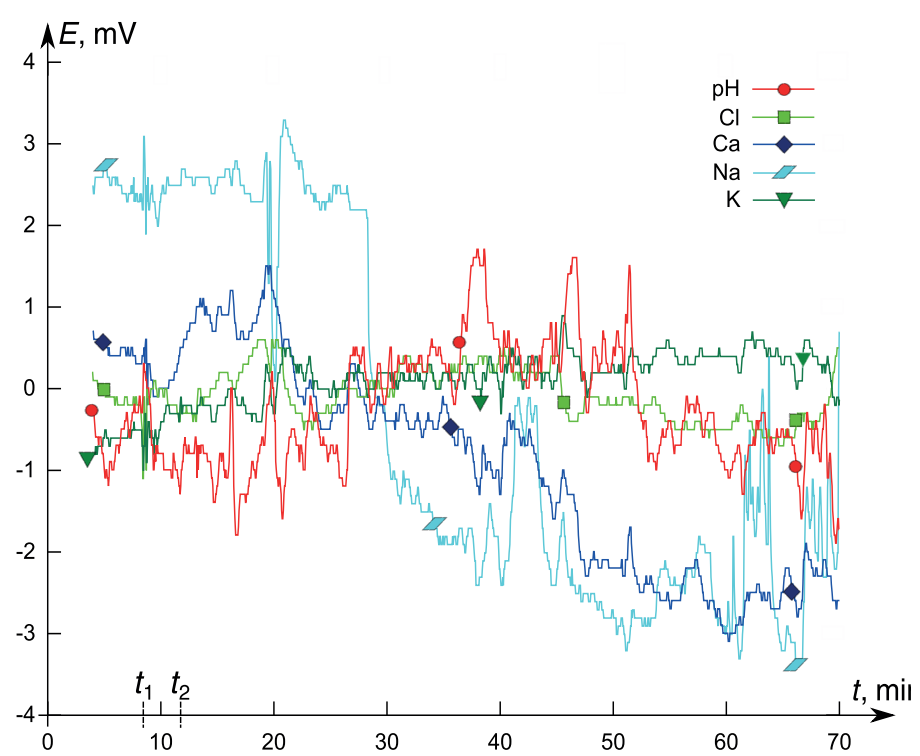

Fig. 5. Time responses of ISEs, the same as in Fig. 4, after data pretreatment 
The signal of the sodium-selective electrode ( $\mathrm{Na}$ ) looks improper. A step change near $27 \mathrm{~min}$., unrelated to the location of the catamaran, can be observed. At the end, between 60 and 70 min., there are some changes in potential. It is most probable that the electrode was incorrectly assembled or failed due to other reasons, although the electrode worked well in the laboratory. This signal cannot be treated as valid.

The signal of the calcium-selective electrode $(\mathrm{Ca})$ has a potential drift. Because the calibration was performed only one time, before experiments, the drift is impossible to compensate.

In the future, working with such electrodes will include two calibrations, before and after experiments. Then, using the linear regression, the drift may be easily removed.

Measurement span of the potassium-selective (K) and chloride-selective $(\mathrm{Cl})$ electrodes is very narrow, below $2 \mathrm{mV}$. The changes in the potentials looks reasonable, but they are very small. It can be concluded that the activities of the ions are near constant in the pond.

The most attractive signal is the one obtained from the $\mathrm{pH}$ electrode. The measurement span is about $4 \mathrm{mV}$. It is also not much but some correlations between the location of the catamaran and the $\mathrm{pH}$ value can be seen. Therefore, a map was prepared and presented in Fig. 6. Positions of the catamaran were acquired by a GPS logger installed on board. Recalculations of potentials to $\mathrm{pH}$ were done after finishing the measurements because the installed software does not allow the calibration parameters of ISEs to be fed into it and the values online to be recalculated. The obtained $\mathrm{pH}$ values were synchronized with GPS data using time stamps. It allows to create a simple map. It is possible to read from the map that the $\mathrm{pH}$ values change dependently of aquatic plants or pollutants which flow in from a drain.

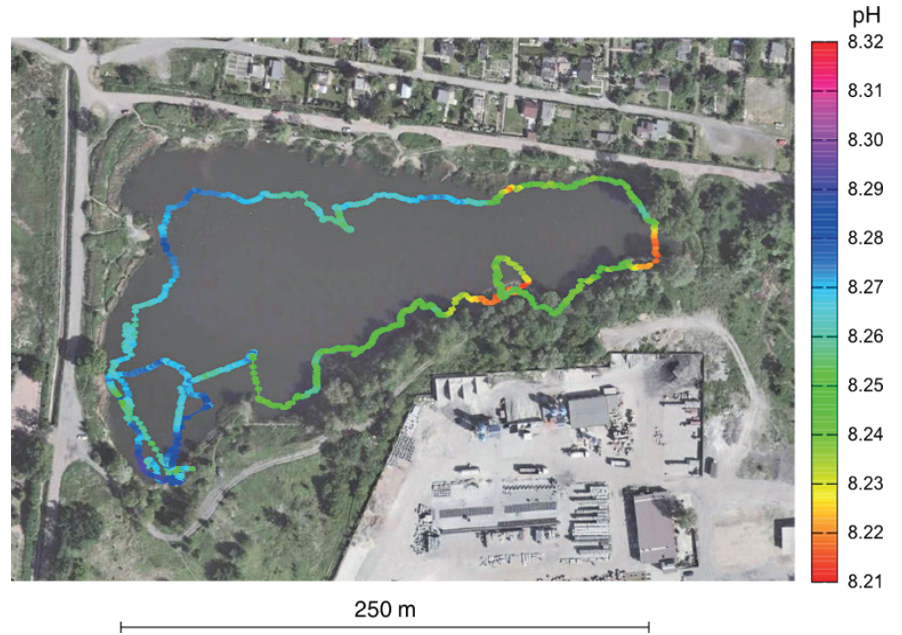

Fig. 6. A pH map of the Cegielnia pond created using the catamaran. The orthophotograph is taken from http://mapy.geoportal.gov.pl

It can be also seen that slightly different values of $\mathrm{pH}$ are observed at the same positions. It results from dynamics of the measurement system. The response time of the $\mathrm{pH}$ electrode is only a few seconds, but other factors, like water mixing near the catamaran, properties of fluids or electronic interferences between ISEs and In-Amps, also affect the dynamics. The response time of the whole system is assessed as a few dozens of seconds. The slower the catamaran moves, the better measurement values are obtained. However, it should be taken into consideration that ISEs have unstable potentials and measurements cannot take too long without calibration.

The driving of the catamaran using the PC gamepad was very comfortable. The wireless $\mathrm{ZigBee}$ range covers the area of the pond. Thanks to applying the microcontroller evaluation board, almost all the components needed for control the catamaran are on board. Other subsystems, except the signal conditioner, are on commercially available boards sold as hobby electronics kits, so the assembly of the system does not consume too much time. The signal conditioner, co-working with ISEs, has a unique construction, therefore it has to be built by the authors. Microcontroller programming environment, delivered together with the evaluation board, allows for easy program development.

\section{Conclusions}

An application of a remote-controlled catamaran for measurements of water parameters was described in the paper. The parameters are: water temperature, $\mathrm{pH}$ and concentrations of chloride, potassium and sodium. The data are transmitted wirelessly to a PC, where they are archived. Some pre-processing is needed in order to remove disturbances, drifts or reject incorrect data. Module construction of electronics allows for easy assembly, which does not require top-level specialists in electronics. Data acquisition is very comfortable and much faster than manual sampling. Using the acquired data, it is possible to perform a high-resolution map illustrating changes of selected water parameter in a reservoir. The elaborated measurement platform is a basis which can be easily modified, developed and adapted to a system with full positioning and sampling autonomy.

Acknowledgements. The authors would like to thank Andrian Hamczyk for help in realizing the project and the Polish Ministry of Science and Higher Education (Bk/213/RAu1/2016) for financial support.

\section{REFERENCES}

[1] M. R. A. Matos, M. T. S. R. Gomes, J. A. B. P. Oliveira, E. Alves, M. A. S. D. A. Cunha, A. Almeida, and A. Rudnitskaya, "Assessment of transition metals toxicity in environmental matrices using potentiometric electrodes: Inorganic mercury(ii) in the seawater as a case study", Electroanalysis 27 (8), 19321938 (2015).

[2] H. Zia, N. R. Harris, G. V. Merrett, M. Rivers, and N. Coles, "The impact of agricultural activities on water quality: A case for collaborative catchment-scale management using integrated wireless sensor networks", Comput. Electron. Agric. 96, 126-138 (2013). 
[3] O. Korostynska, A. Mason, and A. Al-Shamma'a, "Monitoring of nitrates and phosphates in wastewater: current technologies and further challenges", Int. J. Smart Sensing Intell. Syst. 5 (1), 149-176 (2012).

[4] J. Wang, X. li Ren, Y. li Shen, and S.-Y. Liu, "A remote wireless sensor networks for water quality monitoring" in Innovative Computing Communication 7-12 (2010).

[5] K. Murphy, B. Heery, T. Sullivan, D. Zhang, L. Paludetti, K. T. Lau, D. Diamond, E. Costa, N. O'Connor, and F. Regan, "A low-cost autonomous optical sensor for water quality monitoring”, Talanta 132, 520-527 (2015).

[6] S. L. Castro, G. A. Wick, and J. J. Buck, "Comparison of diurnal warming estimates from unpumped Argo data and SEVIRI satellite observations", Remote Sens. Environ. 140, 789-799 (2014).

[7] P.-J. Superville, Y. Louis, G. Billon, J. Prygiel, D. Omanović, and I. Pižeta, "An adaptable automatic trace metal monitoring system for on line measuring in natural waters", Talanta 87 , 85-92 (2011).

[8] M. McLaughlin, J. Brooks, and A. Adeli, "A new sampler for stratified lagoon chemical and microbiological assessments", Environ. Monit. Assess. 186 (7), 4097-4110 (2014).

[9] R. Gwiazda, A. Woźnica, B. Łozowski, M. Kostecki, and A. Flis, "Impact of waterbirds on chemical and biological features of water and sediments of a large, shallow dam reservoir", Oceanol. Hydrobiol. St. 43 (4), 418-426 (2014).

[10] R. Koprowski, Z. Wróbel, A. Kleszcz, S. Wilczyński, A. Woźnica, B. Łozowski, M. Pilarczyk, J. Karczewski, and P. Migula, "Mobile sailing robot for automatic estimation of fish density and monitoring water quality", Biomed. Eng. Online 12 (1), 1-19 (2013).

[11] "The directive of the Minister of Environment from 22 October 2014 on the classification of the status of surface waters and environmental quality standards for priority substances", Journal of Laws of the Republic of Poland, item 1482, (2014).

[12] EC, "Directive 2000/60/EC of the European Parliament and of the Council of 23 October 2000 establishing a framework for Community action in the field of water policy" (2000).

[13] A. Jang, Z. Zou, K. K. Lee, C. H. Ahn, and P. L. Bishop, "Stateof-the-art lab chip sensors for environmental water monitoring", Meas. Sci. Technol. 22, 032001 (2011).

[14] T. Grychowski and L. Kowalski, "The microprocessor mobile device for measurement of low concentration of carbon monoxide in air (in Polish)", Przeglad Elektrotechniczny 87 (7), 90-93 (2011).

[15] A. Wiora, J. Wiora, and A. Kozyra, "Dynamic models of ion-selective electrodes and their interface electronics", Metrol. Meas. Syst. 13 (4), 421-432 (2006).

[16] H.-J. Kim, W.-K. Kim, M.-Y. Roh, C.-I. Kang, J.-M. Park, and K. A. Sudduth, "Automated sensing of hydroponic macronutrients using a computer-controlled system with an array of ion-selective electrodes", Comput. Electron. Agric. 93, 46-54 (2013).

[17] A. Dybko, "Optoelectronic system for water quality monitoring", Bull. Pol. Acad. Sci.-Tech. Sci. 56 (2), 173-175 (2008).

[18] B. Nikolsky and E. Materova, Ion-Selective Electrodes, Leningrad, Khimia, 1980

[19] B. P. Nikolsky Zh. Phys. Khim. 10, 495-510 (1937).

[20] K. A. Rubinson and J. F. Rubinson, Contemporary Instrumental Analysis, New Jersey, Prentice Hall (2000).

[21] K. Stebel, D. Choinski, "Performance improvement for quasi periodical disturbances in $\mathrm{PH}$ control", Adv. Electr. Comput. Eng. 15 (1), 123-134 (2015).
[22] H. Xu, Y. Wang, Z. Luo, and Y. Pan, "A miniature all-solid-state calcium electrode applied to in situ seawater measurement", Meas. Sci. Technol. 24, 125105 (2013).

[23] M. Jabłońska-Czapla, S. Szopa, K. Grygoyć, A. Łyko, and R. Michalski, "Development and validation of HPLC-ICP-MS method for the determination inorganic $\mathrm{Cr}$, As and $\mathrm{Sb}$ speciation forms and its application for Plawniowice reservoir (Poland) water and bottom sediments variability study", Talanta 120 , 475-483 (2014).

[24] B. Krasnodebska-Ostrega, K. Dmowski, E. Stryjewska, and J. Golimowski, "Determination of thallium and other elements (As, $\mathrm{Cd}, \mathrm{Cu}, \mathrm{Mn}, \mathrm{Pb}, \mathrm{Se}, \mathrm{Sb}$, and $\mathrm{Zn}$ ) in water and sediment samples from the vicinity of the zinc-lead smelter in Poland", J. Soil. Sediment. 5, 71-73 (2005).

[25] A. Samecka-Cymerman and A. Kempers, "Concentrations of heavy metals and plant nutrients in water, sediments and aquatic macrophytes of anthropogenic lakes (former open cut brown coal mines) differing in stage of acidification", Sci. Total Environ. 281, 87-98 (2001).

[26] J. Dominik, D. A. L. Vignati, B. Koukal, M.-H. Pereira de Abreu, R. Kottelat, E. Szalinska, B. Baś, and A. Bobrowski, "Speciation and environmental fate of chromium in rivers contaminated with tannery effluents", Eng. Life Sci. 7, 155-169 (2007).

[27] E. Podgorni and M. Rzasa, "Investigation of the effects of salinity and temperature on the removal of iron from water by aeration, filtration, and coagulation", Pol. J. Environ. Stud. 23 (6), 2157-2161 (2014).

[28] D. Anders and M. Rzasa, "The possibility of composting animal waste products", Environ. Prot. Eng. 33 (2), 7-15 (2007).

[29] K. Danielewski, J. Weremczuk, R. Jachowicz, and A. Michalski, "Mobile system for measuring water pollution (in Polish)", Przeglad Elektrotechniczny 9a, 79-82 (2011).

[30] G. Szafrański, W. Janusz, and R. Czyba, "Managing system architecture for multi-rotor autonomous flying platform-practical aspects", Man-Machine Interactions 3 in Advances in Intelligent Systems and Computing 242, 131-138 (2014).

[31] M. Janiak and C. Zieliński, "Control system architecture for the investigation of motion control algorithms on an example of the mobile platform Rex", Bull. Pol. Ac.: Tech. 63 (3), 667-678 (2016).

[32] J.-M. Froidefond and S. Ouillon, "Introducing a mini-catamaran to perform reflectance measurements above and below the water surface", Opt. Express 13, 926-936 (2005).

[33] T. Armstrong, Ship Design and Construction, ch. 45. Catamarans. Society of Naval Architects and Marine Engineers (SNAME) (2004).

[34] G. H. Elkaim, "System identification-based control of an unmanned autonomous wind-propelled catamaran", Control Eng. Pract. 17, 158-169 (2009).

[35] B. Jakubiec, "Fuzzy logic speed controller for brushless dc motor drive [Napęd bezszczotkowego silnika prądu stałego z rozmytym regulatorem prędkości]”, Przegląd Elektrotechniczny 90 (12), 211-213 (2014).

[36] R. Kopka and W. Tarczyński, "Measurement system for determination of supercapacitor equivalent parameters", Metrol. Meas. Syst. 20 (4), 581-590 (2013).

[37] B. Vunderl, M. Zagar, and D. Basch, "Remote control of model vehicles using android mobile devices" in 36th International Convention on Information Communication Technology Electronics Microelectronics (MIPRO), 901-906 (2013). 
[38] P. Liu, W. Farias, S. Gibson, and D. Ross, "Remote control of a robotic boat via the internet" in IEEE International Conference on Information Acquisition 548-553 (2005).

[39] S. Kedar and S. Thakare, Principles of Programming Languages. Technical Publications (2009).

[40] T. W. Schultz, $C$ and the 8051. PageFree Pub. 3 ed., (2004)

[41] W. M. Johnston, J. R. P. Hanna, and R. J. Millar, "Advances in dataflow programming languages", ACM Comput. Surv. 36, 1-34 (2004).

[42] K. N. Whitley, "Visual programming languages and the empirical evidence for and against", J. Visual. Lang. Comput., 8, 109-142 (1997).
[43] Fluka Chemie AG, Buchs, Selectophore Ionophores, Membranes, Mini-ISE (1996).

[44] A. Kozyra, J. Wiora, and A. Wiora, "Calibration of potentiometric sensor arrays with a reduced number of standards", $\mathrm{Ta}$ lanta 98, 28-33 (2012).

[45] S. Zuo, K. Wan, S. Zhou, L. Ye, and S. Ma, "Environmental monitoring and assessment of the water bodies of a pre-construction urban wetland", Environ. Monit. Assess. 186 (11), 7349-7355 (2014).

[46] J. Wiora, "Improvement of measurement results based on scattered data in cases where averaging is ineffective", Sens. Actuator B-Chem. 201, 475-481 (2014). 
